\title{
КОНСТРУКЦИИ СУБЪЕКТ-ОБЪЕКТНЫХ ОТНОШЕНИЙ В ПРОЦЕССЕ ПРОФЕССИОНАЛЬНОГО САМООПРЕДЕЛЕНИЯ *
}

\author{
(C) 2020 Половинко Владимир Семенович \\ доктор экономических наук, профессор, \\ заведующий кафедрой, кафедра региональной экономики и управления человеческими ресурсами \\ Омский государственный университет им. Ф. М. Достоевского, Россия, Омск \\ E-mail:pw3@mail.ru
}

\section{(c) 2020 Диннер Игорь Владимирович}

кандидат экономических наук, доцент, кафедра региональной экономики и управления человеческими ресурсами Омский государственный университет им. Ф. М. Достоевского, Россия, Омск

E-mail: igor-dinner@yandex.ru

В статье рассматриваются вопросы взаимоотношений субъектов и объектов профориентации и профессионального самоопределения. Отмечается возрастающее многообразие субъектов, участвующих в этих процессах. Объектами становятся не только традиционно школьники и выпускники образовательных организаций, но и взрослое население. Рассмотрены отношения через призму их интересов, что позволило уточнить цели и инструменты профессионального самоопределения в склассифицированных авторами ситуациях.

Ключевые слова: профессиональное самоопределение, непрерывное профессиональное развитие, субъекты профессионального самоопределения, объекты профессионального самоопределения, противоречия интересов, профориентационно-образовательные центры, профориентация.

Введение. В современных условиях вопросы профессионального самоопределения трансформируются как в практическом, так и в теоретическом плане. Выбор траектории профессионального развития не заканчивается поступлением в вуз. В течение трудовой жизни человек меняет несколько профессий, поэтому профессиональное самоопределение следует рассматривать как непрерывный процесс. Наиболее остро эти вопросы проявляются в кризисные периоды. Так, в период «коронокризиса» государство и другие субъекты активизировали программы переподготовки населения, как отклик на структурные изменения в экономике и меры снижения безработицы. Несмотря на это, функция «профориентации и профессионального самоопределения» как особый вид деятельности не институциализирована. Она осуществляется на стыке проблем управления организацией, управления персоналом, управления регионом, психологией личности, образования. Ввиду объективности этого процесса, в практике возникают новые субъекты, которые участвуют в обозначенном выше процессе, реализуя свои интересы. Возрастание многообразия как субъектов, так и объектов профессионального самоопределения предопределяет необходимость исследования конструкции их отношений.

Цель исследования состоит в классификации субъектов процесса профессионального самоопределения на основе их интересов и определении направлений взаимодействия с объектами.

Методы исследования. Исследование является результатом обобщения эмпирических материалов, полученных в ходе реализации проекта РФФИ (№ 18-010-00944). Эмпирической основой стали результаты опросов школьников Омской области (9-11 классы, N=11691 чел.), классных руководителей (N=1132 чел.), родителей школьников ( $\mathrm{N}=2701$ чел.), студентов омских вузов ( $\mathrm{N}=844$ чел.), работающих ( $\mathrm{N}=674$ чел.), менеджеров по персоналу Омских предприятий (56 чел.). Были проведены фокус-группы для уточнения полученных в ходе опроса результатов.

Основные результаты исследования. Для решения задачи классификации субъектов профессионального самоопределения в качестве базовой была взята позиция, согласно которой предполагает выделение обобщенных субъектов, частных субъектов и субъектов-участников [7].

\footnotetext{
* Выполнено в рамках проекта РФФИ №№ 19-010-885 А «Противоречия профессионального самоопределения на динамичном рынке труда в условиях цифровой инновационной экономики»
} 
Обозначим, что в вопросах профессионального самоопределения задействованы три обобщенных субъекта: «государство», «работодатель» и «человек».

«Человек» в этой системе отношений выступает как в роли субъекта, так и в роли объекта, что отражает его двойственную роль. С одной стороны, он является активным участником процесса профессионального самоопределения: стремиться осознать, развить, эффективно применить свой трудовой и личностный потенциал при выборе профессии и сферы занятости. С другой стороны, именно на него направлено воздействие всех других субъектов для содействия в формировании его профессиональных. Человек как субъект формирует для себя определенные референтные группы, на которые он ориентируется в своём профессиональном самоопределении. В таблицах 1 и 2 представлен спектр референтного окружения различных объектов профориентации для школьников и студентов.

Эмпирическая база позволила выделить приоритетные интересы школьников в процессе профсамоопределения:

- определиться с выбором профессии, наиболее подходящей его способностям (сформированных или потенциальных компетенций);

- выбрать образовательное учреждение, в котором могут быть развиты необходимые для профессии компетенции;

- соотнести издержки получения образования и деятельности по профессии с имеющимися возможностями

- определиться с траекторией дальнейшей деятельности (трудовая деятельность или получение профессионального образования);

- получить информацию о вариантах занятости, их преимуществах и вытекающих из этого издержках.

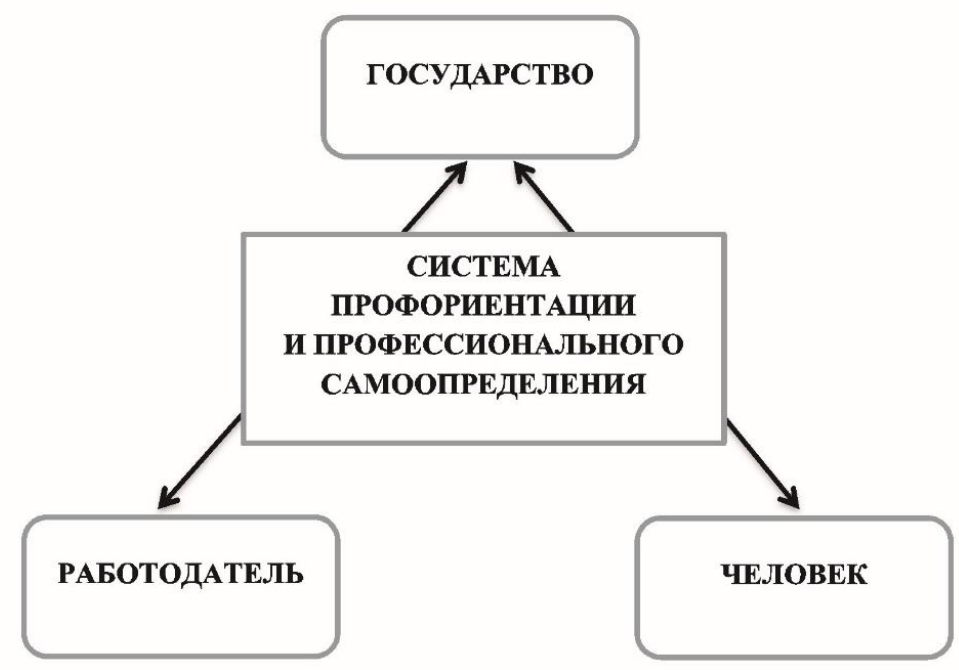

Puc. 1. Обобщенные субъекты системы профориентации.

Таблица 1. Субъекты влияния на выбор школьниками профессии, (\%) *

\begin{tabular}{|l|c|c|c|c|c|}
\hline \multicolumn{1}{|c|}{ На ваш выбор повлияли } & всего & 9кл. & 11 кл. & город & село \\
\hline исключительно самостоятельно & 3,39 & 2,39 & 4,72 & 2,02 & 5,92 \\
\hline семья, родители & 58,17 & 60,16 & 56,19 & 56,12 & 62,56 \\
\hline школа, учителя & 17,18 & 17,12 & 16,86 & 16,09 & 19,26 \\
\hline сверстники, друзья & 5,76 & 6,67 & 4,92 & 5,84 & 5,67 \\
\hline СМИ & 5,41 & 4,75 & 6,86 & 5,81 & 4,75 \\
\hline авторитетные для меня люди & 14,40 & 13,30 & 16,10 & 17,07 & 9,69 \\
\hline $\begin{array}{l}\text { Профориентационные мероприя- } \\
\text { тия других субъектов }\end{array}$ & 13,98 & 13,28 & 14,60 & 14,57 & 13,01 \\
\hline затрудняюсь ответить & 0,09 & 0,10 & 0,00 & 0,09 & 0,08 \\
\hline
\end{tabular}

* Составлено авторами на основе результатов исследования 
Таблица 2. Референтные субъекты профсамоопределения студентов, (\%)

\begin{tabular}{|l|c|c|c|}
\hline \multicolumn{1}{|c|}{ Кто влияет на ваш выбор } & Всего & 1 курс & 4 курс \\
\hline 1. центры профориентации населения & 9,2 & 11,5 & 6,2 \\
\hline 2. служба занятости и другие службы трудоустройства & 17,1 & 18,9 & 14,7 \\
\hline 3. вузовские центры трудоустройства & 26,0 & 30,0 & 21,0 \\
\hline 4. факультеты и кафедры, преподаватели & 61,6 & 64,4 & 58,1 \\
\hline 5. службы по персоналу предприятий, НR-менеджеры & 27,1 & 19,4 & 36,8 \\
\hline 6. организации по молодежному предпринимательству & 8,9 & 9,7 & 7,9 \\
\hline 7. образовательно-тренинговые центры & 14,7 & 14,4 & 15,0 \\
\hline 8. общественные организации по профориентации & 12,7 & 14,6 & 10,2 \\
\hline 9. отраслевые союзы работодателей и пр. & 6,6 & 7,7 & 5,4 \\
\hline
\end{tabular}

Интересы студентов вузов и колледжей, как объектов профессионального самоопределения является:

- конкретизация выбора профессии;

- формирование представлений о карьерном развитии;

- получение практических навыков в деятельности по избранной профессии;

- развитие профессиональных и надпрофессиональных компетенций, для деятельности по профессии;

- выбор формы занятости и вариантов трудоустройства;

- уточнение роли и места трудовых ценностей в системе жизнедеятельности;

- соотнести издержки получения образования и деятельности по профессии с имеющимися возможностями.

Основными субъектами содействия профессиональному самоопределению работающего населения называются «организация в целом» $(17,8 \%)$, «служба управления персоналом» (45,2\%), «руководитель» (34,2\%), друзья (12.7\%), эксперты в профессиональной области (32,2\%). То есть это те факторы, которые зависят от ситуации на предприятии и от профессионального окружения. Занятое население, как объект профессионального самоопределения реализует следующие интересы:

- выполнение трудовых функций в соответствии с объективной оценкой и субъективным восприятием о развитости имеющихся компетенций;

- определение форм и методов развития своих компетенций;

- формирование представлений о карьерном развитии и уверенности в возможностях их реализации в рамках данной организации;

- корректировка места трудовых ценностей в системе жизнедеятельности;

- соотнесение издержек развития компетенций с имеющимися личными возможностями и возможностями организации;

- уточнение формы занятости (продолжить занятость по найму, сменить организацию, фриланс, предпринимательство и пр.).

Представленные данные позволяют представить спектр субъектов и степень их влияния на профессиональное самоопределение.

«Работодатель» как обобщенный субъект заинтересован в том, чтобы привлечь в организацию персонал, соответствующий оперативному и стратегическому развитию, который бы имел необходимую квалификацию, был вовлечен в производственные процессы, способствовал развитию организации. От лица работодателей субъектами могут выступать службы управления персоналом; ассоциации и союзы работодателей, предпринимателей; работники организаций, руководители, формальные и неформальные лидеры и пр.

Роль «Государства» как обобщенного субъекта заключается в том, чтобы, с одной стороны каждый гражданин трудоустроился в соответствии со своими способностями, имел гарантии занятости и перспективы профессионального и личностного развития. С другой стороны, чтобы работодатель имел необходимое количество и качество персонала для своего развития, эффективного производства товаров и/или услуг.

На основе анализа литературы и практики $[3,6,11,8]$, можно выделить еще одну конструкцию субъектов. Существующие субъекты профориентации можно разделить на: специализированные и неспециализированные, формальные и неформальные, а также общественные (государственные, бюджетные, волонтерские) и коммерческие. Было выявлено, что главным 
критерием эффективности субъектов является качество услуг по профессиональному самоопределения, поэтому остановимся на одной из классификаций - специализированные/не специализированные.

К специализированным мы относим те субъекты, основной целью и формой деятельности которых является деятельность по содействию профессиональному самоопределению. Они отличаются профилизацией, должны быть компетентны в области теории, практики и технологии ведения соответствующей деятельности. Неспециализированные субъекты: институты, организации, объединения, отдельные лица, которые содействуют профессиональному самоопределению наряду со своей основной деятельностью. Исследователи отмечают их возрастающее влияние на принятие решения о выборе образовательных организаций и вариантов трудоустройства $[6,13,12]$. Особенно отметим, что чаще всего решение о профессиональном самоопределении принимается в семье, которая при этом сопоставляет ресурсы и возможности семейного бюджета, социального окружения, ценностей, традиций и т.п. Проведенное исследование показывает, что взаимодействие родителей, как субъектов, с объектами профессионального самоопределения, часто носит противоречивый (иногда конфликтный) характер. Методы профессионального самоопределения, с одной стороны, не могут обойтись без привлечения родителей и семейного окружения, с другой стороны, качество их участия требует отдельных программ, направленных на повышение их компетенций как субъектов.

Основные субъект-объектные противоречия, выявленные в этой части исследования:

1. «Чрезмерная специализация». С одной стороны, объект профессионального самоопределения заинтересован в комплексной услуге, включающей и методы диагностики компетенций, перспектив занятости, востребованности в связи с трансформацией профессий и рынка труда. С другой стороны, чрезмерная специализация субъектов разрывает единый процесс профессионального самоопределения на отдельные противоречивые этапы, не позволяет применять сквозные технологии профессионального самоопределения. Поскольку объект (человек, различные социальные группы), является целостным, то актуализируется проблема комплексного проведения мероприятий. Как тенденцию можно отметить их трансформацию в профориентационно-образовательные центры, которые в своей деятельности сочетают психолого-диагностические методы, образовательные, управленческие методы профессионального самоопределения с сопровождением или рекомендациями по трудоустройству и формам занятости (Сириус, Кванториумы, разнообразные центры в регионах).

2. «Профессиональное самоопределение как общественное благо?» С одной стороны, объект профессионального самоопределения продолжает транслировать традиции, согласно которым содействие профессиональному самоопределению осуществляется безвозмездно (бесплатно), воспринимая это как общественное благо, «долг государства». Кроме того, ожидает быстрого эффекта, не готов инвестировать достаточно своего времени для этого процесса. С другой стороны, возрастает стоимость услуг по профессиональному самоопределению, комплексные методики предполагают полного погружения объекта в процесс. Субъект пока еще не осознал комплексности, некоторые параметры процесса (в частности, прогнозирование трансформации профессий, спроса на рынке труда и пр.) не вошли в состав методик.

Субъект - объектные отношения перспективно выстраивать по следующим направлениям:

- специализация программам профессионального самоопределения в зависимости от специфики объекта (школьники, студенты, родители, категории работающего и неработающего населения и т.д.);

- реализация программ на основе современных комплексных методик, сочетающих изучение личности, рынка труда и образовательных услуг;

- получение экономического (дохода для негосударственных субъектов и выполнение объема государственных услуг для государственных субъектов) и социального (удовлетворенность потребителей, достижение целевых индикаторов) результата;

- институализация деятельности по содействию профессиональному самоопределению как услуги;

- наличии квалифицированных сотрудников и волонтеров, задействованных в программах профессионального самоопределения;

- привлечении референтных групп родите- 
лей, работодателей, для формирования вектора профессионального самоопределения.

Другим основанием классификации является разделение субъектов профессионального самоопределения по критерию «возмездность предоставляемых услуг».

Общественные субъекты транслируют интересы государства, регионов, организаций в обеспечении рынка труда соответствующими человеческими ресурсами. Особую роль среди бюджетных выполняют образовательные организации (общего, среднеспециального и высшего образования). Однако, государственные, бюджетные субъекты склонны к бюрократизированным формам отношений как между другими субъектами, а также в рамках субъектобъектных взаимодействий. Коммерческие субъекты профессионального самоопределения возникают как услуга специализированных субъектов. Рыночный характер их функционирования предопределяет особые межсубъектные и субъект-объектные отношения.

В этом плане возникает целая серия противоречий. Согласованность между субъектами возможна только на основе согласования их интересов, что в условиях конкуренции достигается весьма непросто. Немаловажным фактором является социальная направленность профессионального самоопределения и недостаточная интституализация современных методов. Поэтому требуются механизмы конкурсной, грантовой и другой поддержки.

Заключение. Изменение предметной области деятельности по профессиональному самоопределению повлекло за собой изменение состава субъектов. Возникновение новых субъектов происходит стихийно и связано с неадекватным восприятием профессионального самоопределения как непрерывного комплексного процесса, которая традиционно воспринимается как профинформирование и профдиагностика. Необходимо обратить внимание и на то, что субъекты все больше функционирует в рыночных отношениях. Поэтому считаем перспективным исследование интересов субъектов, проектирование процесса и методов с учетом согласования интересов субъектов и уточнения потребностей объектов профессионального самоопределения.

\section{Библиографический список}

1. Бродовская Е.В., Домбровская А.Ю., Пырма Р.В., Синяков А.В., Азаров А.А. Влияние цифровых коммуникаций на формирование профессиональной культуры российской молодежи: результаты комплексного прикладного исследования //Мониторинг общественного мнения: Экономические и социальные перемены. 2019. № 1.- С. 228-251.

2. Грачева Н.А. Профориентация и миграция молодежи как важнейшие элементы развития регионального рынка труда//Уровень жизни населения регионов России. 2016. № 3(201). - С.67-76.

3. Дмитриева Д.В., Харькова О.А. Теоретические аспекты профессионального самоопределения// Инновационная наука. 2020. № 11.- С. 175-178.

4. Избрасова Н.Ю., ЛетучеваЛ.А. Модель формирования профессионально-личностного самоопределения обучающейся молодежи на основе сетевого взаимодействия организаций дополнительного и профессионального образования//Инновационное развитие профессионального образования. 2016. № 2 (10).- С. 82-87.

5. Лях П. П. Профессиональное самоопределение: от профессионального выбора до образования// Ученые заметки ТОГУ. 2018. № 1 (9).- С. 408-412.

6. Пожарская Е.Л., ДебердееваН.А. Психологические особенности профессионального самоопределения и ценностные ориентации молодежи на этапе профессионального обучения в высшей школе// Успехи современной науки. 2017. № 4 (5).-С. 191-198.

7. Половинко В.С. Управление персоналом: системный подход и его реализация: Монография/Под науч. ред. Ю. Г. Одегова.- М.: Информ-Знание, 2002. С. 224-232.

8. Профориентация и профессиональное самоопределение в контексте непрерывного профессионального развития: диссертация ... кандидата экономических наук: 08.00.05 / Диннер Игорь Владимирович; [Место защиты: ФГБОУ ВО «Омский государственный университет им. Ф. М. Достоевского»], 2018. - 233 с.

9. Dinner I., Polovinko V. Contradictions of the choice of employment forms by students of the Omsk region in conditions of the digital economy development// he 13th International Days of Statistics and Economics Edited by: Conference Proceedings / University of Economics, Prague. 2019. pp.300-308. 
10. Ebert Ph., Freibichler W. Nudge Management: Applying Behavioural Science to Increase Knowledge Worker Productivity. Journal of Organization Design. 2017. Vol. 6. No. 4. https://doi.org/10.1186/s41469-017-0014-1 (дата обращения: 10.11.2020).

11. Kaemmerer E. Professional Orientation - Career Pathways // Professional Orientation Five Steps to Decision on a School and Occupation. Professional Orientation Elementary School Program. Belgrade, 2011. p. 80. URL: http://profesionalnaorijentacija.org/wpcontent/uploads/2011/12/Professional_orientation__elementary_school_ program.pdf (дата обращения: 26.11.2020). 